\title{
Multi-body dynamics in full-vehicle handling analysis
}

S Hegazy, H Rahnejat* and K Hussain

Department of Mechanical Engineering, University of Bradford, West Yorkshire, UK

\begin{abstract}
This paper presents a multidegrees-of-freedom non-linear multibody dynamic model of a vehicle, comprising front and rear suspensions, steering system, road wheels, tyres and vehicle inertia. The model incorporates all sources of compliance, stiffness and damping, all with non-linear characteristics. The vehicle model is created in ADAMS (automatic dynamic analysis of mechanical systems) formulation. The model is used for the purpose of vehicle handling analysis. Simulation runs, in-line with vehicle manoeuvres specified under ISO and British Standards, have been undertaken and reported in the paper.
\end{abstract}

Keywords: multi-body dynamics, suspensions, steering, non-linear characteristics, simulations

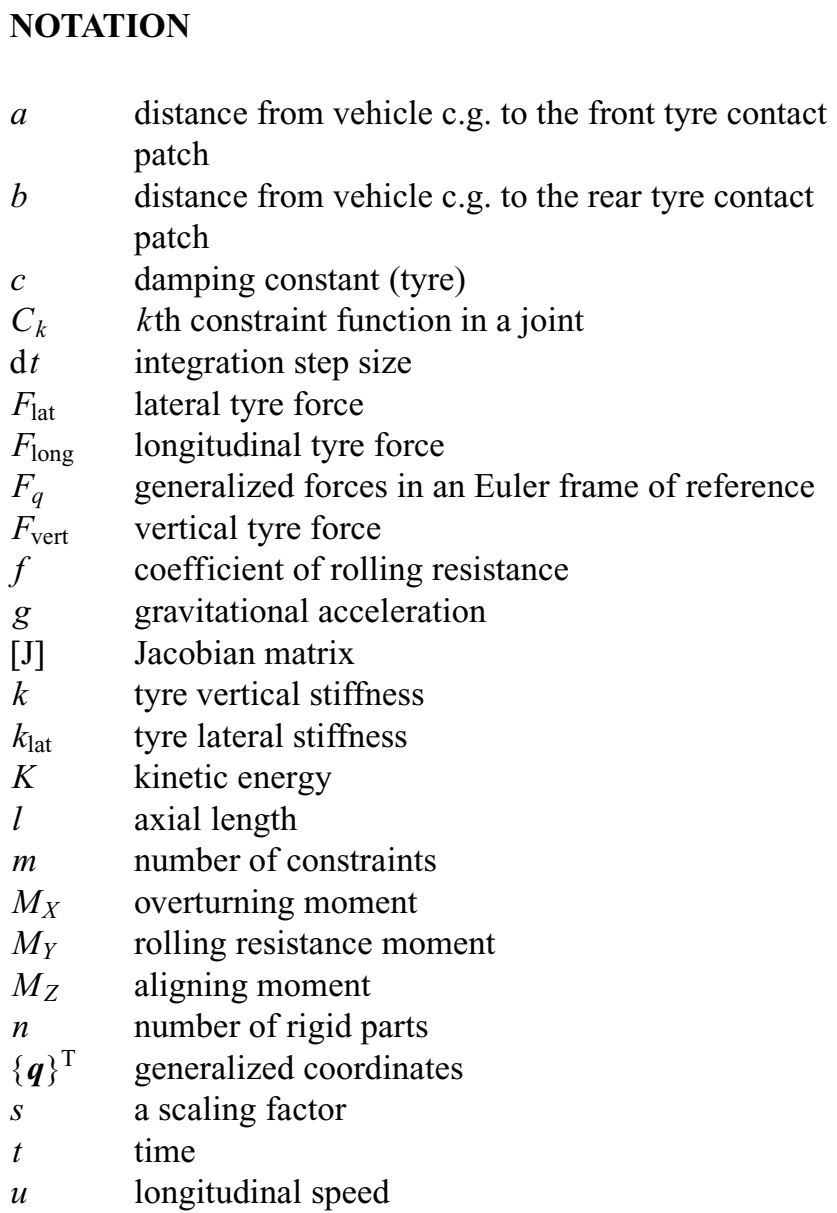

The MS was received on 19 January 1999 and was accepted after revision for publication on 2 June 1999.

* Corresponding author: Department of Mechanical Engineering, University of Bradford, Bradford, West Yorkshire BD7 1DP, UK.

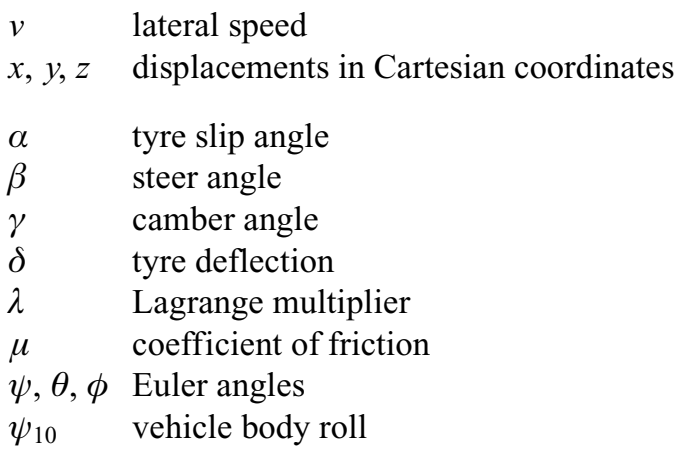

\section{Superscript}

rate of change with time

\begin{tabular}{|c|c|}
\hline Sub & pts \\
\hline $\mathrm{f}$ & front tyre \\
\hline$i, j$ & body $i$ relative to body $j$ \\
\hline$k$ & $\begin{array}{l}k \text { th holonomic constraint function } \\
\text { rear tyre }\end{array}$ \\
\hline
\end{tabular}

\section{INTRODUCTION}

Multi-body dynamics has played an increasingly important role in the analysis of vehicle motions ever since the introduction of linear vehicle dynamic models by Segel [1] for lateral accelerations of up to $0.3 \mathrm{~g}$. However, linear models include significant assumptions:

(a) small steering inputs at normal constant vehicle speeds,

Proc Instn Mech Engrs Vol 213 Part K 
(b) linear tyre behaviour with slip and camber angles,

(c) smooth flat roads and

(d) lateral tyre forces not altering with small changes in vertical tyre forces.

There are, in fact, many sources of non-linearity in suspension kinematics, steering characteristics, tyre properties and in the vehicle inertial dynamics in roll, pitch and yaw motions when it is subjected to longitudinal, lateral and vertical forces. Compliance characteristics in vehicle suspension systems are usually of a non-linear nature.

Vehicle handling analysis, through multi-body dynamics, received an impetus with the work of McHenry [2]. A considerable volume of literature deals with the issue of ride comfort of vehicles in single-event perturbations such as negotiating a bump or a ditch. Other analyses are concerned with vehicle handling characteristics in response to various intended manoeuvres. The performance characteristics of a vehicle in all such tests are profoundly affected by its suspension, a primary function of which is ride comfort. Another function of the suspension system is to maintain the road wheels at correct orientations to the road surface, and thus control the directional response of the vehicle during the various manoeuvres. Often, for good ride comfort the suspension system should provide a relatively low vertical stiffness, which conflicts with the requirements of good handling analysis which usually calls for a relatively high value of stiffness. These conflicting requirements have led to the gradual introduction of independent suspensions, adjustable systems and active elements. Suspensions may also be designed so that the stiffness of the bushes contributes to the overall roll stiffness of the vehicle.

Chace [3] and Orlandea et al. $[4,5]$ have investigated a three-dimensional vehicle model with 42 rigid-body degrees of freedom. They subjected their model to a severe steering ramp input of $210^{\circ}$ in $0.4 \mathrm{~s}$ while travelling at a forward tangential speed of $75 \mathrm{~km} / \mathrm{h}$. The simulation results were presented for lateral acceleration, roll angle and yaw velocity. Allen et al. [6] reported two vehicle models: a linear and a non-linear dynamic model. They also proposed a numerical procedure designed to permit efficient vehicle dynamic analysis on a microcomputer of the type in use at that time. Their analyses include a steady state model for the determination of side force coefficients, a stability factor and time of manoeuvre for lateral/ directional control. The steady state and dynamic models included a tyre model for comprehensive slip. Pacejka [7] introduced handling diagrams for the analysis of the steady state behaviour of a vehicle. A handling diagram was defined as the plot of lateral acceleration versus the difference between the slip angles of rear and front tyres. Naude and Steyn [8] have investigated a computer simulation for the handling characteristics of a vehicle, performing a double-lane change manoeuvre in order to perform a transient handling simulation. They have also presented a driver model to steer the vehicle along a prescribed path during their closed-loop simulation study.

In order to study the handling behaviour of a vehicle, the tyre cornering forces must be carefully determined. The simplest form of tyre modelling involves the computer storage of a large amount of measured tyre data which are used in conjunction with an interpolation method to represent the tyre forces characterized by the measured data. This method is currently used in general purpose dynamics software. Most tyre models currently used in vehicle dynamic simulations involve empirical representations of the measured tyre data. A comprehensive review of the tyre models is given by Pacejka and Sharp [9].

Pacejka et al. [10] employed a tyre formula to describe the characteristics of side force and self-aligning torque as functions of slip angle, and the longitudinal force (brake force) as a function of longitudinal slip, with good accuracy. The formula is limited to steady state conditions during pure cornering and pure braking. This tyre model contains 53 coefficients, which define the tyre stiffness components, tyre geometry and peak force variations with slip angle or longitudinal slip. The formula also takes into account the curvature factors, which are functions of vertical load and camber angle. The model has come to be known as the 'magic formula', representing an empirical method for fitting tyre data.

Allen et al. $[\mathbf{1 1}, \mathbf{1 2}]$ investigated an expanded version of vehicle simulation tyre models for a full range of operating conditions (slip, camber and normal load) on both paved and off-road surfaces. Their tyre model simulations are based upon a composite slip formulation as a function of lateral and longitudinal slip. Xia and Willis [13] have studied the effect of tyre cornering stiffness on the vehicle frequency response, using two different models. These include a non-linear vehicle model and a linear bicycle model that has two degrees of freedom. The non-linear vehicle model employs a multi-body dynamics formulation and includes a non-linear steering system, full suspension geometry, non-linear suspension forces and the non-linear tyre forces and moments. The linear model was considered as a linear time-invariant system with two degrees of freedom and included the evaluation of lateral velocity and yaw rate of the vehicle with constant forward speed.

In fact, vehicle ride and handling analysis has accounted for one of the largest growth areas in the application of multi-body dynamics. Various literature reviews are provided by Kortüm and Sharp [14], Kortüm and Schiehlen [15] and Kübler and Schiehlen [16].

\section{DESCRIPTION OF THE VEHICLE MODEL}

The full vehicle model comprises vehicle mass and inertia, front and rear double-wishbone suspensions, a rack and pinion steering system, road wheels and tyres. Vehicle motions are described in terms of the fixed global frame of 
reference $X, Y, Z$ shown in Fig. 1. Local part frames of reference $x_{i}, y_{i}, z_{i}$ are attached to all of the moving parts $i$. A generic formulation method, based upon Lagrange's equation for constrained systems, is employed for the derivation of equations of motion for all parts in the model in a body 3-1-3 Euler frame of reference (see Section 3).

\subsection{Suspensions and steering system models}

The front and rear suspensions are of double-wishbone configuration. Each quarter-suspension comprises two control arms, referred to as the lower and upper control arms respectively. The control arms are connected to the vehicle body by elastic rubber bushings with non-linear characteristics. Typical characteristic curves for these are shown in Fig. 2. The bushings provide appropriate longitudinal and torsional compliance which influences the dive (during braking) and squat (during acceleration) characteristics of the vehicle. The shock absorber is attached to the vehicle underbody and the lower control arm. A bump stop is situated on the lower control arm, while a rebound stop is located on the upper control arm. Typical characteristics for these elements are also shown in Fig. 2.

The upper steering column is connected to the steering wheel and to the vehicle body by revolute joints, and to the lower steering column by a universal joint (see Fig. 3). The pinion is connected to the steering column by a universal joint, and to the vehicle body by a cylindrical joint. The steering rack is connected to the vehicle body by a translational joint. The coupler connects between the cylindrical and translational joints, describing their motion relationship which is $166 \mathrm{~mm}$ of rack travel resulting from $1148.4^{\circ}$ of pinion rotation. The steering rack is connected to the tie rods by universal joints. The tie rods are attached to the steering knuckles by spherical joints which represent the ball joints, also shown in Fig. 3. The steering knuckles, in turn, are connected to the upper and lower control arms by spherical joints in appropriate locations which define the inclination of the steering axis.

\subsection{Tyre model}

There are six components of force and moment generated as a result of tyre interaction with the road. These are the vertical tyre force, longitudinal traction force and lateral force, as well as the self-aligning moment, the overturning moment and the rolling resistance moment (see Fig. 4a). The tyre model reported here does not include the overturning moment.

\subsubsection{Tyre vertical force}

The radial tyre contact force, acting in the radial plane of the tyre, has a component that acts in the direction of the contact normal at the tyre-road contact patch. This component is used to calculate the tyre vertical force. The radial force is dependent on tyre deflection and its rate of change, both measured along the tyre vertical directional vector [17]. The deflection is obtained by an instantaneous evaluation of the distance between the position of the wheel centre and the road surface plane in the contact patch. The time rate of change in deflection is obtained by the vector scalar product of the instantaneous tyre radius vector and the wheel centre global velocity. The quantities thus obtained are employed to obtain the stiffness and damping contributions to the tyre vertical force, as indicated by the first and second terms in equation (1):

$$
F_{\text {vert }}=k \delta-c \frac{\partial \delta}{\partial t}
$$

\subsubsection{Tyre lateral force}

There are two alternative methods for determination of the tyre lateral force. These are through the use of an equation

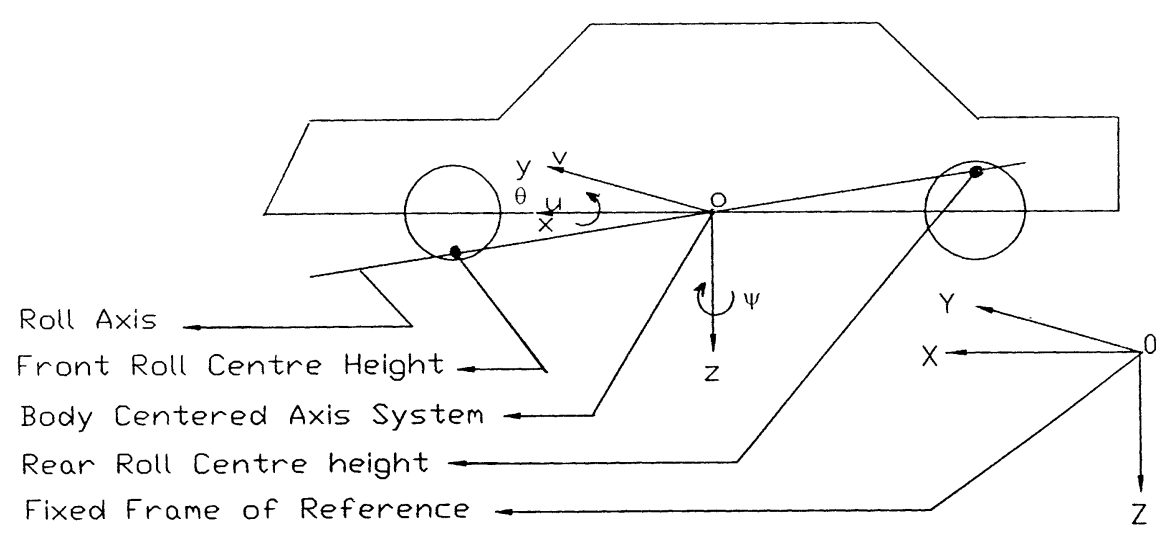

Fig. 1 Axis system for the vehicle model 


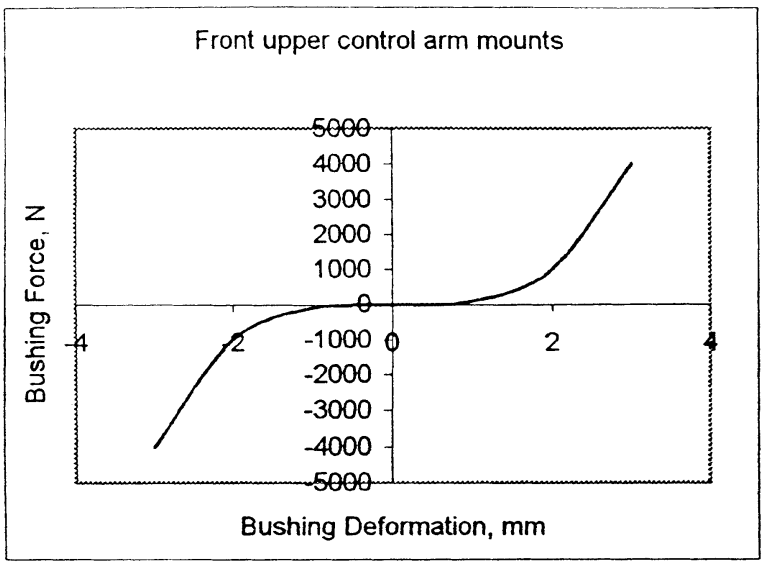

(a) Sub-frame mounts

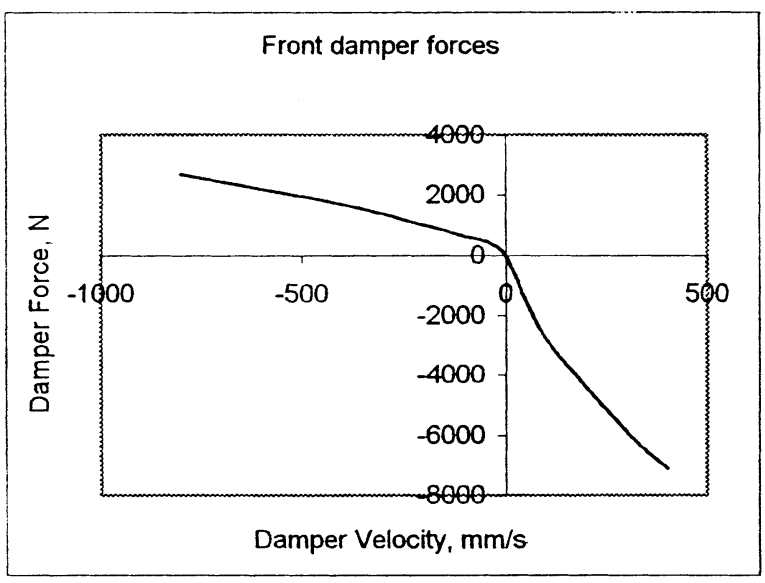

(c) Front damper characteristics

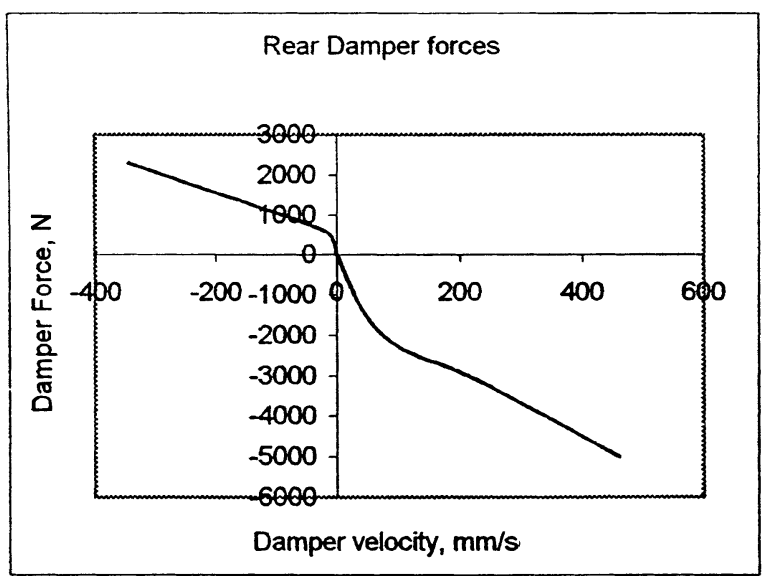

(e) Rear damper characteristics

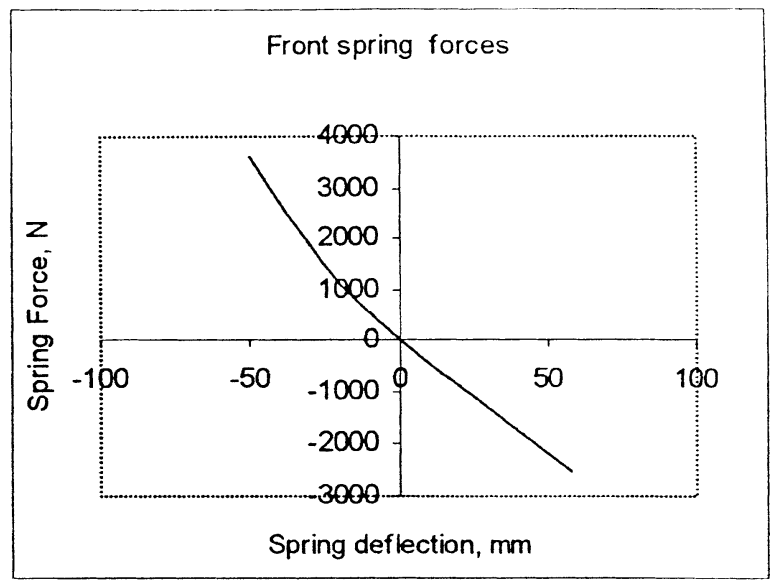

(b) Front spring characteristics

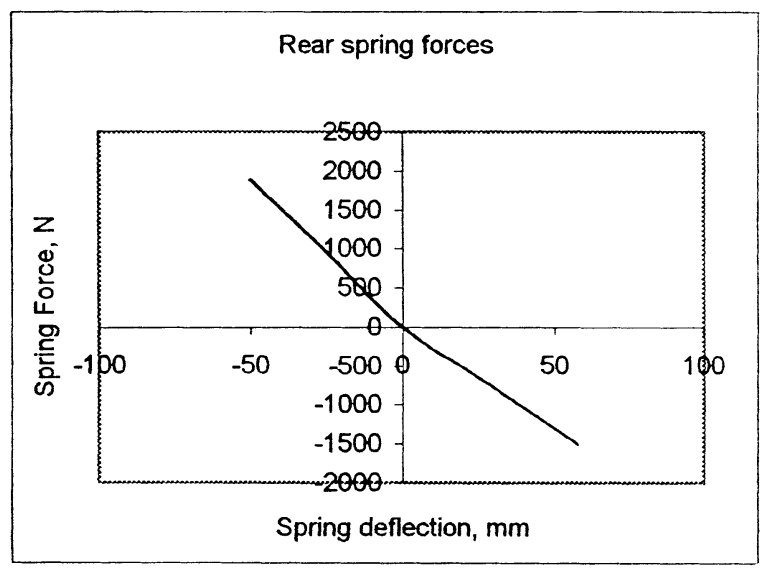

(d) Rear spring characteristics

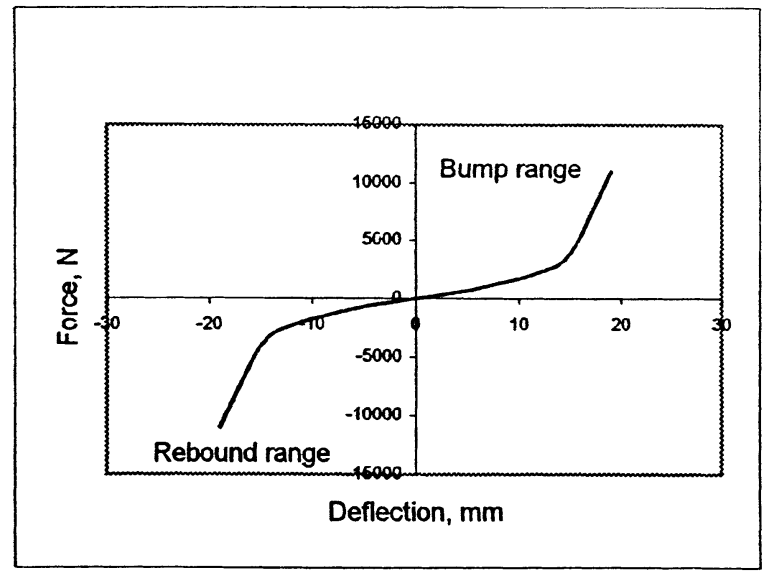

(f) Bump and Rebound stop force characteristics

Fig. 2 Sources of compliance in the vehicle model 
Parts

\begin{tabular}{|l|l|}
\hline 3 & Steering rack \\
\hline 4 & Steering wheel \\
\hline 5 & Upper steering col. \\
\hline 6 & Lower steering col. \\
\hline 7 & Pinion \\
\hline 8 & Lower wishbone left \\
\hline 9 & Lower wishbone right \\
\hline 10 & Upper wishbone left \\
\hline 11 & Upper wishbone right \\
\hline 12 & Steering knuckle left \\
\hline 13 & Steering knuckle right \\
\hline 14 & Tie rod left \\
\hline 15 & Tie rod right \\
\hline 16 & Upper damper left \\
\hline 17 & Upper damper right \\
\hline 18 & Lower damper left \\
\hline 19 & Lower damper right \\
\hline 32 & Front tyre left \\
\hline 33 & Front tyre right \\
\hline
\end{tabular}

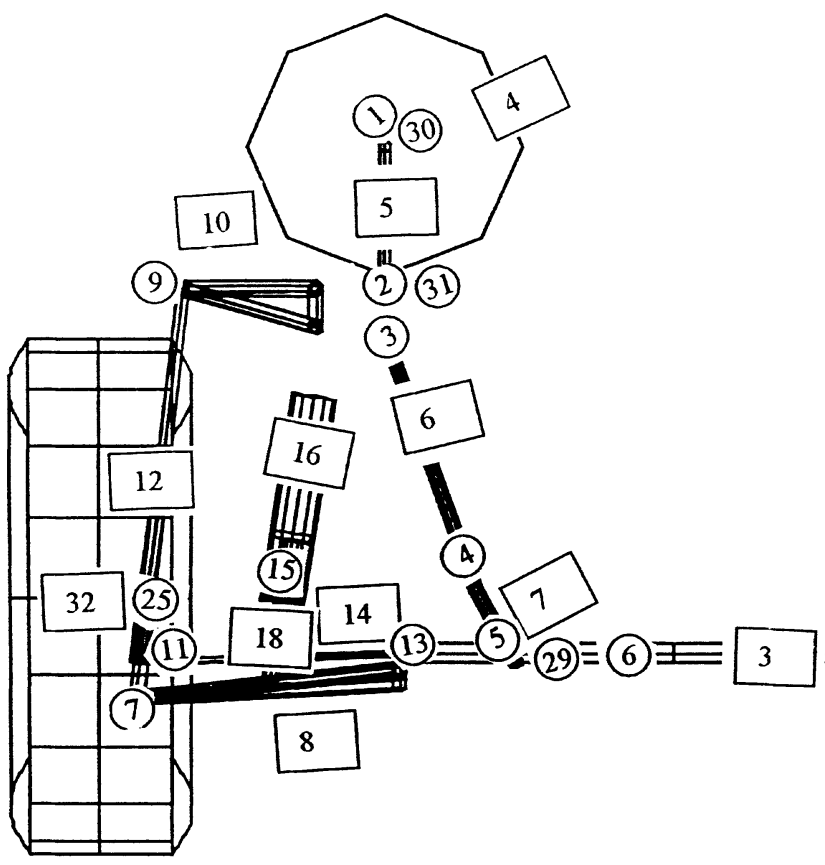

Joints

\begin{tabular}{|l|l|}
\hline 1 & Revolute joint /26 \\
\hline 2 & Revolute joint /33 \\
\hline 3 & Universal joint \\
\hline 4 & Universal joint \\
\hline 5 & Cylindrical joint /54 \\
\hline 6 & Translational joint /61 \\
\hline 7 & Spherical joint \\
\hline 8 & Spherical joint \\
\hline 9 & Spherical joint \\
\hline 10 & Spherical joint \\
\hline 11 & Spherical joint \\
\hline 12 & Spherical joint \\
\hline 13 & Universal joint \\
\hline 14 & Universal joint \\
\hline 15 & Cylindrical joint \\
\hline 16 & Cylindrical joint \\
\hline 25 & Revolute joint \\
\hline 26 & Revolute joint \\
\hline 29 & Coupler \\
\hline 30 & Motion \\
\hline 31 & Motion \\
\hline
\end{tabular}

Fig. 3 Schematic representation of front vehicle suspension and steering system

method or by an interpolation process [17]. The equation method, employed in this analysis uses the following simplified equation to generate the lateral force:

$$
F_{\text {lat }}=\mu F_{\text {vert }}\left(1-\mathrm{e}^{-k_{\text {lat }}|\alpha|}\right)
$$

where

$$
\alpha=\tan ^{-1}\left(\frac{v+l \psi_{10}}{u}\right)-\beta
$$

For $\alpha=\alpha_{\mathrm{f}}, l=a$ and $\alpha=\alpha_{\mathrm{r}}, l=-b$. The coefficient of K00199 (C) IMechE 1999 friction $\mu$ changes from the initial static to the instantaneous dynamic conditions as shown in Fig. $4 b$.

\subsubsection{Tyre longitudinal force}

The rolling resistance force and the traction (or braking) force together constitute the tyre longitudinal reaction force [17]. The rolling resistance force is calculated by multiplying the coefficient of rolling resistance, $f$, with the vertical force. The traction force is obtained by multiplying the instantaneous value of the coefficient of friction with the vertical force. These forces oppose the motion of the 


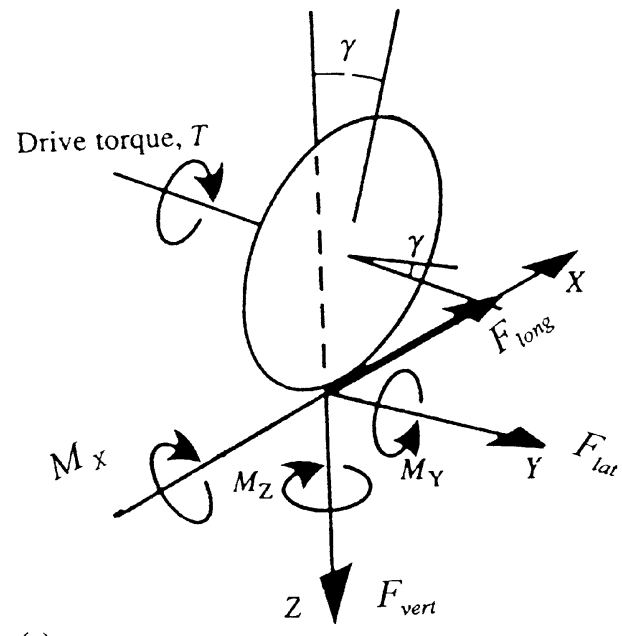

(a)

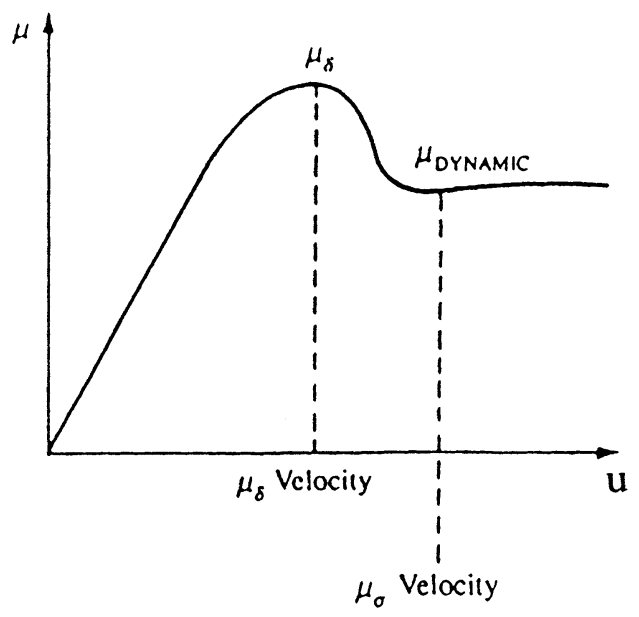

(b)

Fig. 4 (a) Tyre forces and moments and (b) variation in coefficient of friction with longitudinal speed

vehicle at the road surface contact patch. The combined force is referred to as the longitudinal force:

$$
F_{\text {long }}=(\mu-f) F_{\text {vert }}
$$

\subsection{Vehicle model}

The full vehicle model is an assembly of the front suspension and steering system, the rear suspension, the road wheels and tyres. It also includes the vehicle body, represented by its mass and inertial components. Tables 1 and 2 provide the list of all parts and all constraints in the full vehicle model.

The Grüebler-Kützbach expression can be used to determine the available degrees of freedom in the vehicle model. There are 34 parts in the vehicle model, excluding ground (see Table 1). The number of constraints for each joint, coupler and specified motions is given in Table 2 . Thus:

$$
\begin{aligned}
n_{\mathrm{DOF}} & =6 n-\sum \text { constraints }=6 n-m=6(34)-110 \\
& =94
\end{aligned}
$$

\section{METHOD OF FORMULATION AND SOLUTION}

\subsection{Equations of motion}

There are 34 parts in the multi-body model, the motion of each of which can be described in terms of the generalized coordinates, $q$, by Lagrange's equation for constrained systems:

$$
\frac{\mathrm{d}}{\mathrm{d} t}\left(\frac{\partial K}{\partial \dot{q}}\right)-\frac{\partial K}{\partial q}-F_{q}+\sum_{k=1}^{m} \lambda_{k} \frac{\partial C_{k}}{\partial q}=0
$$

The generalized coordinates are given by $\{q\}^{\mathrm{T}}=\left\{\begin{array}{llll}x & y & z & \psi\end{array}\right.$ $\theta \varphi\}$, where the rotational components are the Euler angles in body $3-1-3$ successive rotations.

The reaction forces in the multibody system are given by the summation term in equation (6) along each of the generalized coordinates. These are introduced as holonomic algebraic constraint functions, $C_{k}$. Therefore, the assembly of parts can be represented mathematically in a manner that conforms to the required dynamic functions of the system. Under dynamic conditions, equation (6) provides six equations of motion per part in the vehicle system model.

\subsection{Holonomic constraint functions}

Ideal functions in all mechanisms are assured by appropriate use of constraints in the form of joints or attachments. Each joint or assembly attachment introduces constraint functions in the form of non-linear algebraic equations. Table 2 lists the different types of joint employed in the assembly of various parts in the vehicle model. Typical constraint functions for a number of these joints are given below.

For a spherical joint, for instance between the steering left front knuckle and its upper wishbone, the following three constraints pertaining to an at-point condition exist:

$$
C_{k=1-3}=x_{22,24}=y_{22,24}=z_{22,24}=0
$$

For a revolute joint, as in the attachment between the upper steering column and the steering wheel, the at-point constraint is supplemented by two-axis orthogonality conditions around the rotation $\psi_{5,4}$ :

$$
C_{k=1-3}=x_{5,4}=y_{5,4}=z_{5,4}=0
$$


Table 1 Mass and inertial properties in the vehicle model

\begin{tabular}{|c|c|c|c|c|c|c|c|c|}
\hline \multirow[b]{2}{*}{ No. } & \multirow[b]{2}{*}{ Part name } & \multirow[b]{2}{*}{ Mass (kg) } & \multicolumn{3}{|c|}{ Centre of mass location (mm) } & \multicolumn{3}{|c|}{ Inertia $\left(\mathrm{kg} / \mathrm{mm}^{2}\right)$} \\
\hline & & & $X$ & $Y$ & $Z$ & $I_{x x}$ & $I_{y y}$ & $I_{z z}$ \\
\hline 1 & Ground & - & - & - & - & - & - & - \\
\hline 2 & Vehicle body & 1185 & 1200 & 0 & 160 & $4.83 \mathrm{E}+08$ & $2.404 \mathrm{E}+09$ & $2.482 \mathrm{E}+09$ \\
\hline 3 & Steering rack & 4.1 & -697 & 0 & -128.8 & $1.84 \mathrm{E}+05$ & $1.84 \mathrm{E}+05$ & 460 \\
\hline 4 & Steering wheel & 2.1 & 674 & 396 & 574 & $1.3 \mathrm{E}+04$ & $1.3 \mathrm{E}+04$ & $2.4 \mathrm{E}+04$ \\
\hline 5 & Upper steering column & 1.6 & 295.5 & 396 & 450.5 & $8.5 \mathrm{E}+04$ & $8.5 \mathrm{E}+04$ & 80 \\
\hline 7 & Pinion & 0.8 & -639 & 243.5 & -92 & 3200 & 3200 & 77 \\
\hline 8 & Lower wishbone left & 6 & -447 & -489.3 & -166.6 & $5 \mathrm{E}+04$ & $1 \mathrm{E}+05$ & $1.5 \mathrm{E}+05$ \\
\hline 9 & Lower wishbone right & 6 & -447 & 489.3 & -166 & $5 E+04$ & $1 \mathrm{E}+05$ & $1.5 \mathrm{E}+05$ \\
\hline 10 & Upper wishbone left & 0.6 & -553 & -556.4 & 373 & 3000 & 300 & 3000 \\
\hline 11 & Upper wishbone right & 0.6 & -553 & 556.4 & 373 & 3000 & 300 & 3000 \\
\hline 12 & Steering knuckle left & 14 & -516.3 & -767.4 & -39.5 & $8 \mathrm{E}+04$ & $1.3 \mathrm{E}+05$ & $8 \mathrm{E}+04$ \\
\hline 13 & Steering knuckle right & 14 & -516.3 & 767.4 & -39.5 & $8 \mathrm{E}+04$ & $1.3 \mathrm{E}+05$ & $8 \mathrm{E}+04$ \\
\hline 14 & Tie rod left & 0.7 & -701.3 & -549 & -134.9 & 8200 & 8200 & 27 \\
\hline 17 & Upper damper right & 15.12 & -572.9 & 507.3 & 128.1 & $1.4 \mathrm{E}+05$ & $1.4 \mathrm{E}+05$ & $2.7 \mathrm{E}+04$ \\
\hline 18 & Lower damper left & 1.68 & -574.9 & -538.8 & -74.2 & 6000 & 6000 & 200 \\
\hline 19 & Lower damper right & 1.68 & -574.9 & 538.8 & -74.2 & 6000 & 6000 & 200 \\
\hline 20 & Lower wishbone left & 1.8 & 2526 & -522 & -177 & $1.5 \mathrm{E}+04$ & $1 \mathrm{E}+05$ & $2.4 \mathrm{E}+04$ \\
\hline 21 & Lower wishbone right & 1.8 & 2526 & 522 & -177 & $1.5 \mathrm{E}+04$ & $1 \mathrm{E}+05$ & $2.4 \mathrm{E}+05$ \\
\hline 22 & Upper wishbone left & 1.3 & 2513 & -579.5 & 92.6 & 7000 & $1.5 \mathrm{E}+04$ & $2.1 \mathrm{E}+04$ \\
\hline 23 & Upper wishbone right & 1.3 & 2513 & 579.5 & 92.6 & 7000 & $1.5 \mathrm{E}+04$ & $2.1 \mathrm{E}+04$ \\
\hline 24 & Steering knuckle left & 13.8 & 2520 & -764 & -39 & $8.2 \mathrm{E}+04$ & $1.31 \mathrm{E}+05$ & $8.2 \mathrm{E}+04$ \\
\hline 25 & Steering knuckle right & 13.8 & 2520 & 764 & -39 & $8.2 \mathrm{E}+04$ & $1.31 \mathrm{E}+05$ & $8.2 \mathrm{E}+04$ \\
\hline 26 & Tie rod left & 0.7 & 2700.4 & -555.1 & -141.8 & 8200 & 8200 & 27 \\
\hline 27 & Tie rod right & 0.7 & 2700.4 & 555.1 & -141.8 & 8200 & 8200 & 27 \\
\hline 28 & Upper damper left & 15.12 & 2478.6 & -543.7 & 109.4 & $1.4 \mathrm{E}+05$ & $1.4 \mathrm{E}+05$ & $2.7 \mathrm{E}+04$ \\
\hline 29 & Upper damper right & 15.12 & 2478.6 & 543.7 & 109.4 & $1.4 \mathrm{E}+05$ & $1.4 \mathrm{E}+05$ & $2.7 \mathrm{E}+04$ \\
\hline 30 & Lower damper left & 1.68 & 2469.6 & -559.8 & -95.4 & 6000 & 6000 & 200 \\
\hline 31 & Lower damper right & 1.68 & 2469.6 & 559.8 & -95.4 & 6000 & 6000 & 200 \\
\hline 32 & Front tyre left & 42.2 & -573 & -767.1 & -51 & $9 \mathrm{E}+05$ & $9 \mathrm{E}+05$ & $1.59 \mathrm{E}+06$ \\
\hline 33 & Front tyre right & 42.2 & -573 & 767.1 & -51 & $9 \mathrm{E}+05$ & $9 \mathrm{E}+05$ & $1.59 \mathrm{E}+06$ \\
\hline
\end{tabular}

and

$$
\begin{aligned}
& C_{k=4}=\sin \theta_{5,4} \sin \phi_{5,4}=0 \quad \text { and } \\
& C_{k=5}=\sin \theta_{5,4} \cos \phi_{5,4}=0
\end{aligned}
$$

A cylindrical joint, for instance between the pinion gear and the vehicle body, with the degrees of freedom $z_{7,10}$, $\psi_{7,10}$, has the following constraint functions:

$$
\begin{aligned}
C_{k=1}= & x_{7,10}\left(\sin \psi_{7,10} \cos \theta_{7,10} \sin \phi_{7,10}\right. \\
& \left.\quad-\cos \psi_{7,10} \cos \phi_{7,10}\right) \\
= & \\
C_{k=2}= & y_{7,10}\left(\cos \psi_{7,10} \cos \theta_{7,10} \cos \phi_{7,10}\right. \\
& \left.\quad-\sin \psi_{7,10} \sin \phi_{7,10}\right) \\
= & 0 \quad \sin \theta_{7,10} \sin \phi_{7,10}=0 \\
C_{k=3} & \\
C_{k=4}= & \sin \theta_{7,10} \cos \phi_{7,10}=0
\end{aligned}
$$

The $z_{3,10}$ translational motion of the steering rack with respect to the vehicle body has the constraint functions

$$
\begin{array}{rl}
C_{k=1}= & x_{3,10}\left(\sin \psi_{3,10} \cos \theta_{3,10} \sin \phi_{3,10}\right. \\
& \left.\quad-\cos \psi_{3,10} \cos \phi_{3,10}\right) \\
= & 0 \\
C_{k=2}= & y_{3,10}\left(\cos \psi_{3,10} \cos \theta_{3,10} \cos \phi_{3,10}\right. \\
& \left.\quad-\sin \psi_{3,10} \sin \phi_{3,10}\right) \\
= & 0 \quad \sin \psi_{3,10} \cos \phi_{3,10}+\cos \psi_{3,10} \cos \theta_{3,10} \sin \phi_{3,10} \\
C_{k=3} & 0 \\
C_{k=4}= & -\cos \psi_{3,10} \sin \theta_{3,10}=0 \\
C_{k=5}= & \sin \psi_{3,10} \sin \theta_{3,10}=0
\end{array}
$$

The steering motion for the vehicle manoeuvre is given as a function of time (see Fig. 5). This presents a single constraint function as 
Table 2 Assembly constraints in the vehicle model

\begin{tabular}{|c|c|c|c|c|c|c|c|}
\hline \multirow[b]{2}{*}{ No. } & \multirow[b]{2}{*}{ Constraint type } & \multirow[b]{2}{*}{ Part I } & \multirow[b]{2}{*}{ Part J } & \multicolumn{3}{|c|}{ Joint location (mm) } & \multirow{2}{*}{$\begin{array}{l}\text { No. of } \\
\text { constraints }\end{array}$} \\
\hline & & & & $X$ & $Y$ & $Z$ & \\
\hline 1 & Revolute joint/26 & Steering wheel & Upper steering column & 674 & 396 & 574 & 5 \\
\hline 2 & Revolute joint $/ 33$ & Upper steering column & Vehicle body & 295.5 & 396 & 450.5 & 5 \\
\hline 3 & Universal joint & Upper steering column & Lower steering column & -114 & 396 & 317 & 4 \\
\hline 4 & Universal joint & Lower steering column & Pinion & -597 & 271 & -40 & 4 \\
\hline 5 & Cylindrical joint/54 & Pinion & Vehicle body & -639 & 234.5 & -92 & 4 \\
\hline 7 & Spherical joint & Lower wishbone left & Steering knuckle left & -580.3 & -731.9 & -191.4 & 3 \\
\hline 8 & Spherical joint & Lower wishbone right & Steering knuckle right & -580.3 & 731.9 & -191.4 & 3 \\
\hline 9 & Spherical joint & Upper wishbone left & Steering knuckle left & -550.8 & -670.4 & 376.6 & 3 \\
\hline 10 & Spherical joint & Upper wishbone right & Steering knuckle right & -550.8 & 670.4 & 376.6 & 3 \\
\hline 11 & Spherical joint & Steering knuckle left & Tie rod left & -705.1 & -730.9 & -140.9 & 3 \\
\hline 12 & Spherical joint & Steering knuckle right & Tie rod right & -705.1 & 730.9 & -140.9 & 3 \\
\hline 13 & Universal joint & Steering rack & Tie rod left & -697.5 & -367 & -128.8 & 4 \\
\hline 14 & Universal joint & Steering rack & Tie rod right & -697.5 & 367 & -128.8 & 4 \\
\hline 17 & Spherical joint & Lower wishbone left & Steering knuckle left & 2569.7 & -743.4 & -192 & 3 \\
\hline 18 & Spherical joint & Lower wishbone right & Steering knuckle right & 2569.7 & 743.4 & -192 & 3 \\
\hline 19 & Spherical joint & Upper wishbone left & Steering knuckle left & 2584.9 & -705.9 & 100 & 3 \\
\hline 20 & Spherical joint & Lower wishbone right & Steering knuckle right & 2584.9 & 705.9 & 100 & 3 \\
\hline 21 & Spherical joint & Steering knuckle left & Tie rod left & 2704.2 & -742.4 & -148.7 & 3 \\
\hline 22 & Spherical joint & Steering knuckle right & Tie rod right & 2704.2 & 742.4 & -148.7 & 3 \\
\hline 23 & Cylindrical joint & Upper damper left & Lower damper left & 2471.6 & -556.2 & -49.9 & 4 \\
\hline 24 & Cylindrical joint & Upper damper right & Lower damper right & 2471.6 & 556.2 & -49.9 & 4 \\
\hline 25 & Revolute joint & Steering knuckle left & Front tyre left & -573 & -780.8 & -51 & 5 \\
\hline 26 & Revolute joint & Steering knuckle right & Front tyre right & -573 & 780.8 & -51 & 5 \\
\hline 27 & Revolute joint & Steering knuckle left & Rear tyre left & 2577 & -756 & -51 & 5 \\
\hline 28 & Revolute joint & Steering knuckle right & Rear tyre right & 2577 & -756 & -51 & 5 \\
\hline 29 & Coupler & Joint 54 & Joint 61 & & & & 1 \\
\hline 30 & Motion & & Joint 26 & & & & 1 \\
\hline 31 & Motion & & Joint 33 & & & & 1 \\
\hline
\end{tabular}

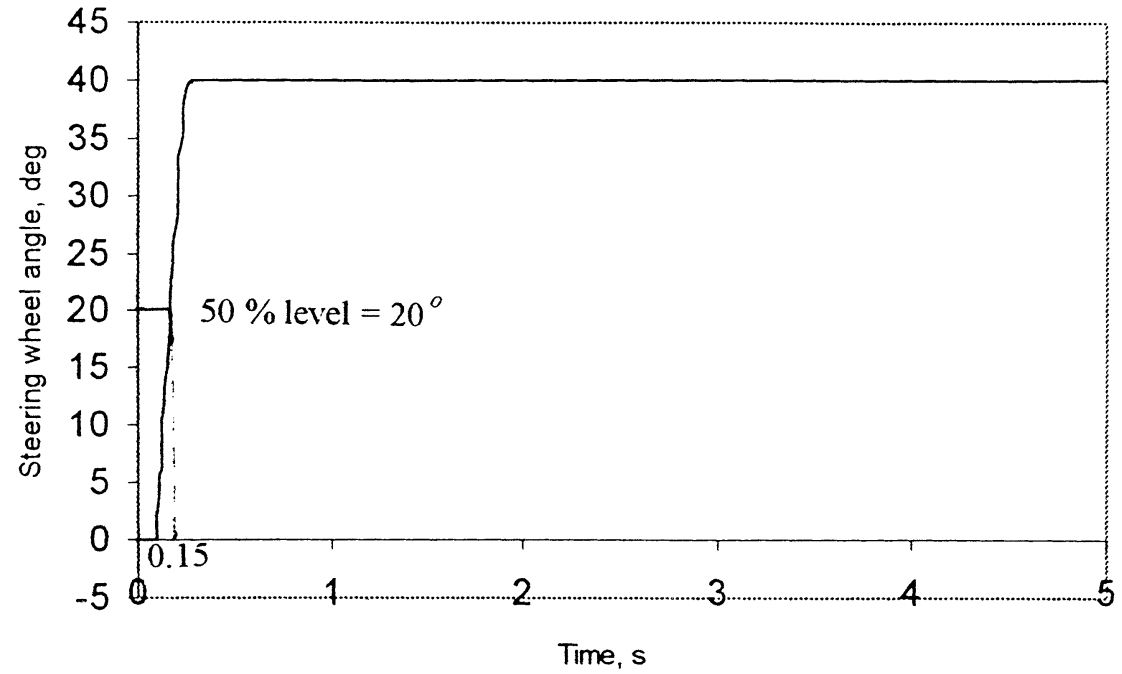

Fig. 5 Steering wheel angle input with time

$\beta= \begin{cases}0, & t \leqslant 0.1 \\ 0.11 \pi\left\{1+\sin \left[\frac{\pi(t-0.1)}{0.2}-\frac{\pi}{2}\right]\right\}, & 0.1 \leqslant t \leqslant 0.3 \\ 0.22 \pi, & t \geqslant 0.3\end{cases}$
There are, in fact, 110 constraint functions in the vehicle model, similar to constraint functions (8) to (19).

\subsection{Formation of the Jacobian matrix}

The set of differential equations of motion (Section 3.1), the scalar constraint functions (Section 3.2), the applied forces 
and the compliance functions (e.g. tyre forces, bushing reactions) have to be solved in discrete small time steps. The vector of unknowns includes the system state variables (position, velocity and acceleration of all parts) and the Lagrange multipliers representing the joint reactions. Thus, in matrix form the set of equations is represented by

$$
[\mathbf{J}]\{\boldsymbol{q}, \lambda\}^{\mathrm{T}}=\left\{\boldsymbol{F}_{q}\right\}
$$

The Jacobian matrix is of the following form:

$$
[\mathbf{J}]=\left[\begin{array}{cc}
{\left[\frac{s}{\mathrm{~d} t} \frac{\partial K}{\partial q}+\frac{\partial K}{\partial q}\right]} & {\left[\frac{\partial C}{\partial \lambda}\right]} \\
{\left[\frac{\partial C}{\partial q}\right]} & {[0]}
\end{array}\right]
$$

The Jacobian matrix contains many zero entries, thus being referred to as sparse. The Jacobian matrix is also quite large in dimensions, as it embodies appropriate coefficients for six equations of motion for all the vehicle parts listed in Table 1, and all the formulated constraint functions for the joints in the model (see Table 2 and Section 3.2). In fact fewer than 10 per cent of all the elements of the matrix are usually non-zero. The solution to the differential-algebraic set of equations is obtained in small variable time steps, $\mathrm{d} t$, employing a predictor-corrector technique with a Newton -Raphson method for the solution of a non-linear set of simultaneous equations, and step-by-step integration using a 'stiff' algorithm for widely split eigenvalue problems [18-20].

\section{FULL-VEHICLE SIMULATION STUDIES AND DISCUSSION}

An important measure of vehicle performance is its handling characteristics when subjected to a given steering input. The stability of the vehicle under various specified manoeuvres can be investigated. Typical vehicle handling simulations include transient cornering, lane changing and slalom motions, including double-lane changes, with or without braking. The current analysis is concerned with a transient cornering manoeuvre with a constant forward velocity. A number of important parameters are investigated. These include the tyre forces, spring forces, damper forces and bump and rebound stop forces, particularly on the inside wheels as the vertical force diminishes with increasing lateral acceleration. The vertical excursion of the front and rear roll centre heights is also of interest as a large displacement of these can affect the vehicle stability.

Most modern vehicles can undergo cornering manoeuvres with lateral accelerations of up to $0.8 \mathrm{~g}$, during which body roll in the region $2-8^{\circ}$ can occur. The specified manoeuvre should represent a realistic test of vehicle behaviour under severe conditions. Test procedures have been specified by international standards in ISO 74011988 or in the British Standard BS AU 230:1989 [21].

Figure 6 shows an animated output for the transient manoeuvre during a simulation time of $5 \mathrm{~s}$. Five hundred time steps of simulation were undertaken, after an initial static equilibrium analysis is carried out to ensure vehicle placement at the kerb height.

Figures $7 \mathrm{a}$ and $\mathrm{b}$ show the vertical tyre forces during the specified manoeuvre. The tyre forces at time $t=0$ correspond to the initial static equilibrium position. Due to the weight distribution of the vehicle, the rear tyres carry approximately 54.5 per cent of the total weight. The corresponding front and rear roll centre heights are 70.3 and $76.7 \mathrm{~mm}$ above the ground respectively. During the manoeuvre, as the steering wheel input increases from 0 to $40^{\circ}$, the outside wheels generate larger vertical tyre forces owing to the inertial forces, which effect a load transfer
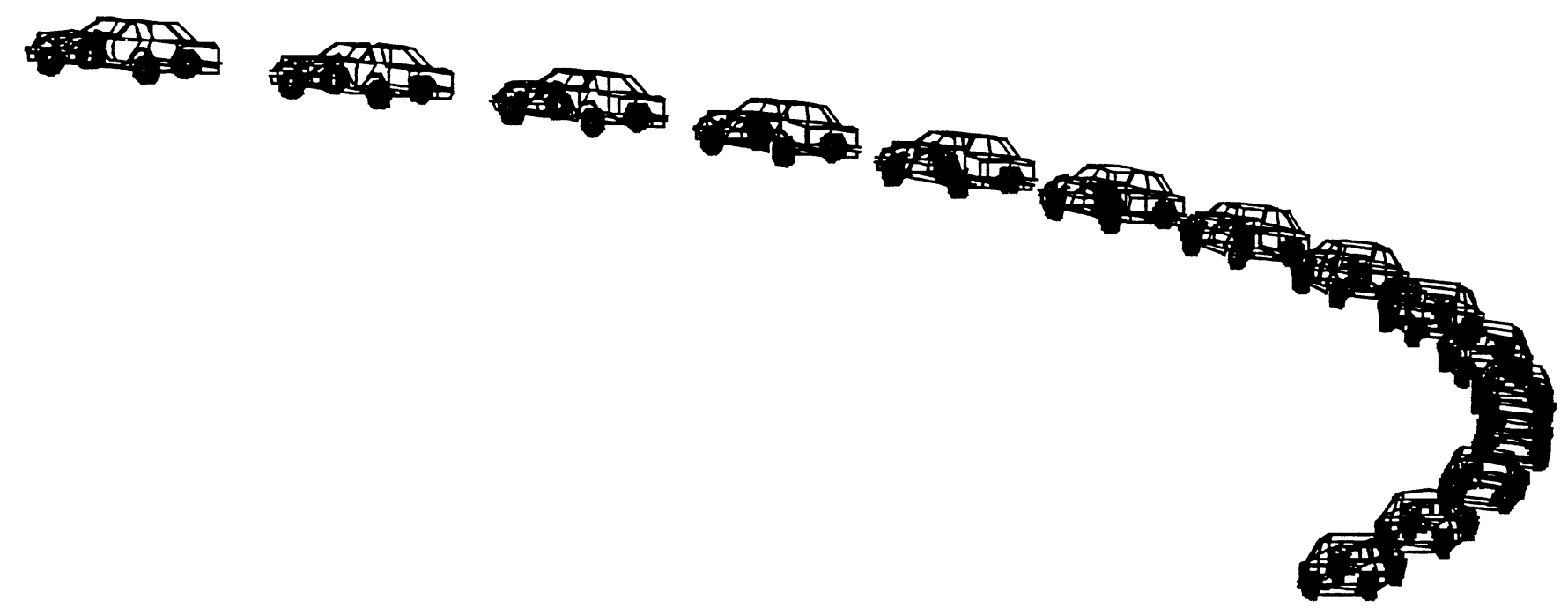

Fig. 6 Vehicle manoeuvre for $5 \mathrm{~s}$ of simulations 


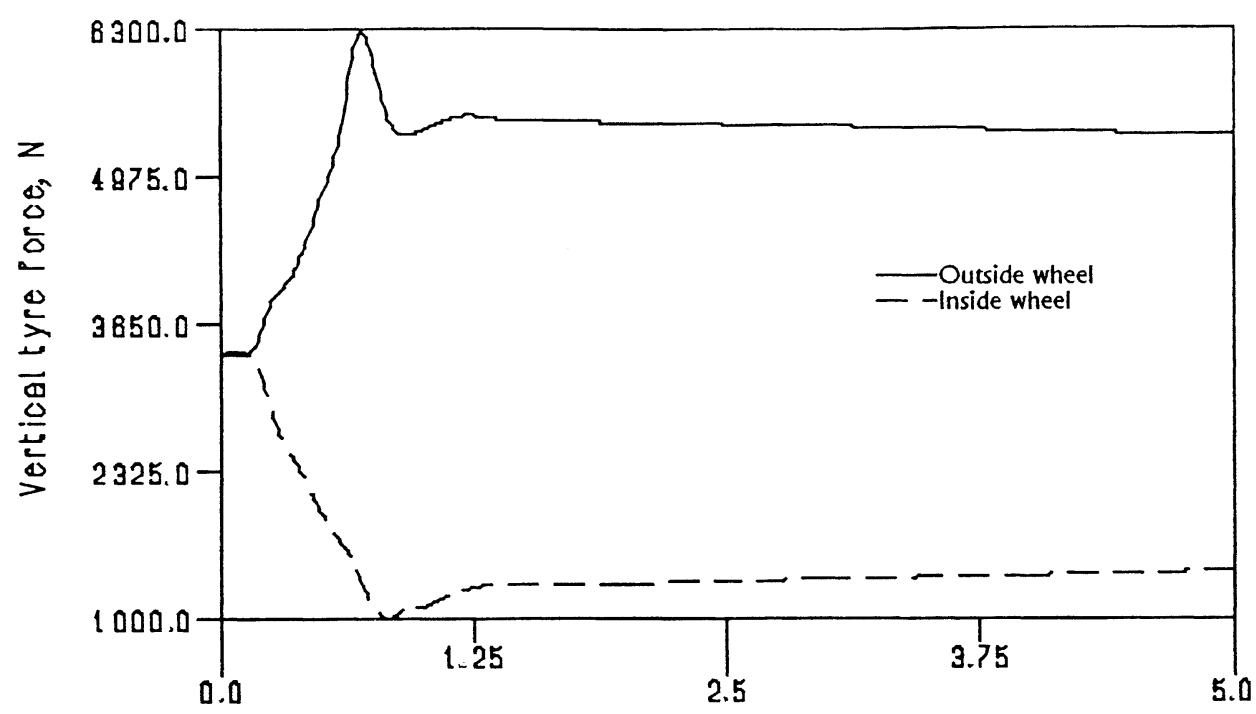

(a)

Time, $s$

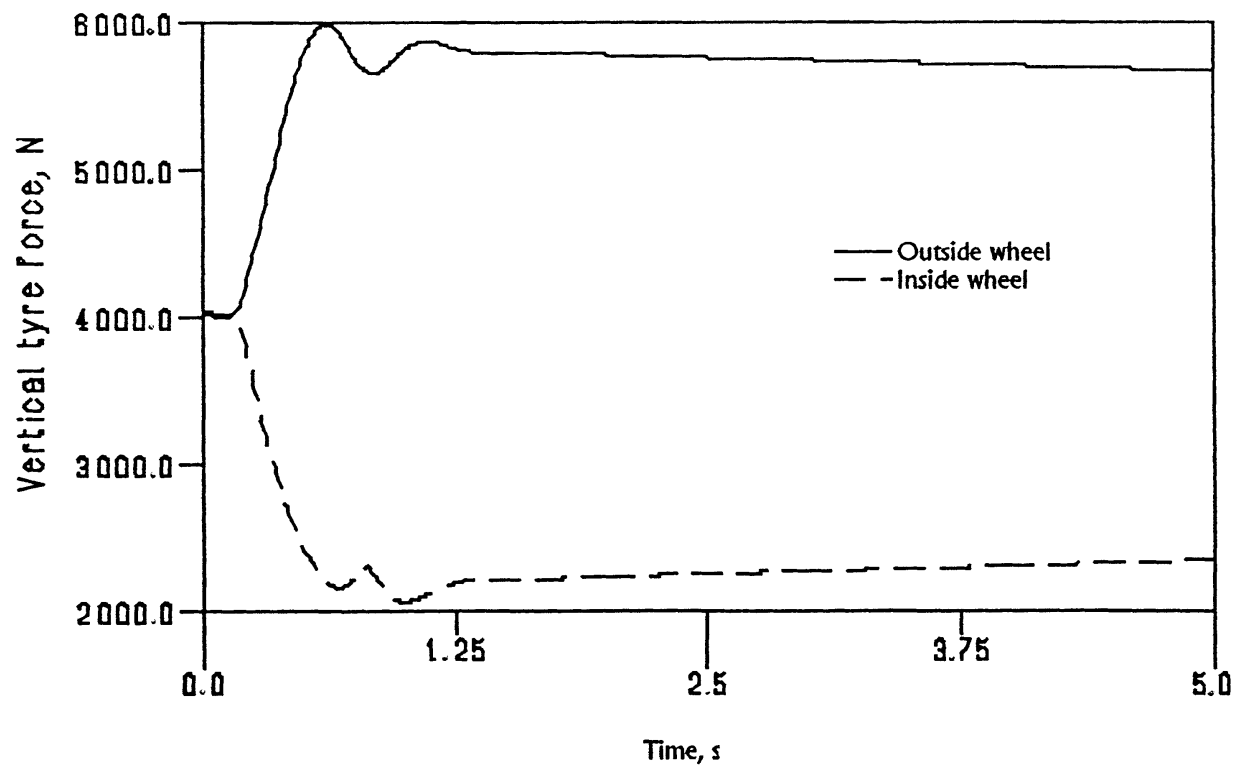

Fig. 7 Vertical forces for (a) front tyres and (b) rear tyres

from right to left. Therefore, the vertical tyre forces on the outside wheels increase and generate a bump stop force in the opposite direction. Consequently, the vertical tyre forces on these wheels decrease. The inside wheels are subjected to the opposite effect owing to rebound. This trend can be observed in Figs $7 \mathrm{a}$ and $\mathrm{b}$. The bump and rebound forces are shown in Figs $8 \mathrm{a}$ and $\mathrm{b}$, corroborating this argument. The reduction in the vertical tyre force on the inside wheels is an indication of vehicle instability. It can be observed that for this simulation the inside wheels off-load rapidly before a steady condition is reached through body roll, suspension articulation and generation of shock absorber reactions. The inside wheel tyres still carry sufficient vertical forces to maintain a good contact with the road. It should also be noted that the transient response dies down quickly after a few oscillations, this being an indication of an acceptable response of the vehicle to the steering input. The front and rear roll centres undergo vertical excursions towards the ground with downward articulation of the control arms (see Fig. 9a).

Reference [21] outlines the standard test for the transient response of a vehicle subjected to a step input steering

K00199 (C) IMechE 1999 


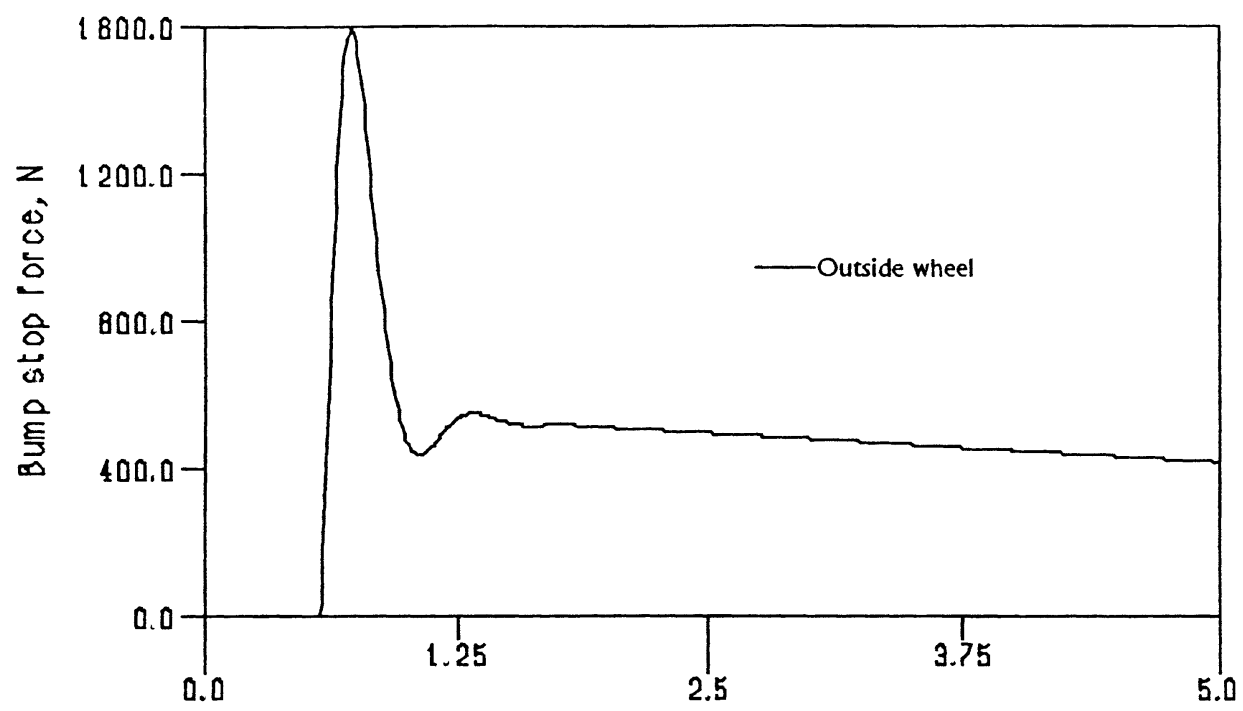

(a)

Time, $s$

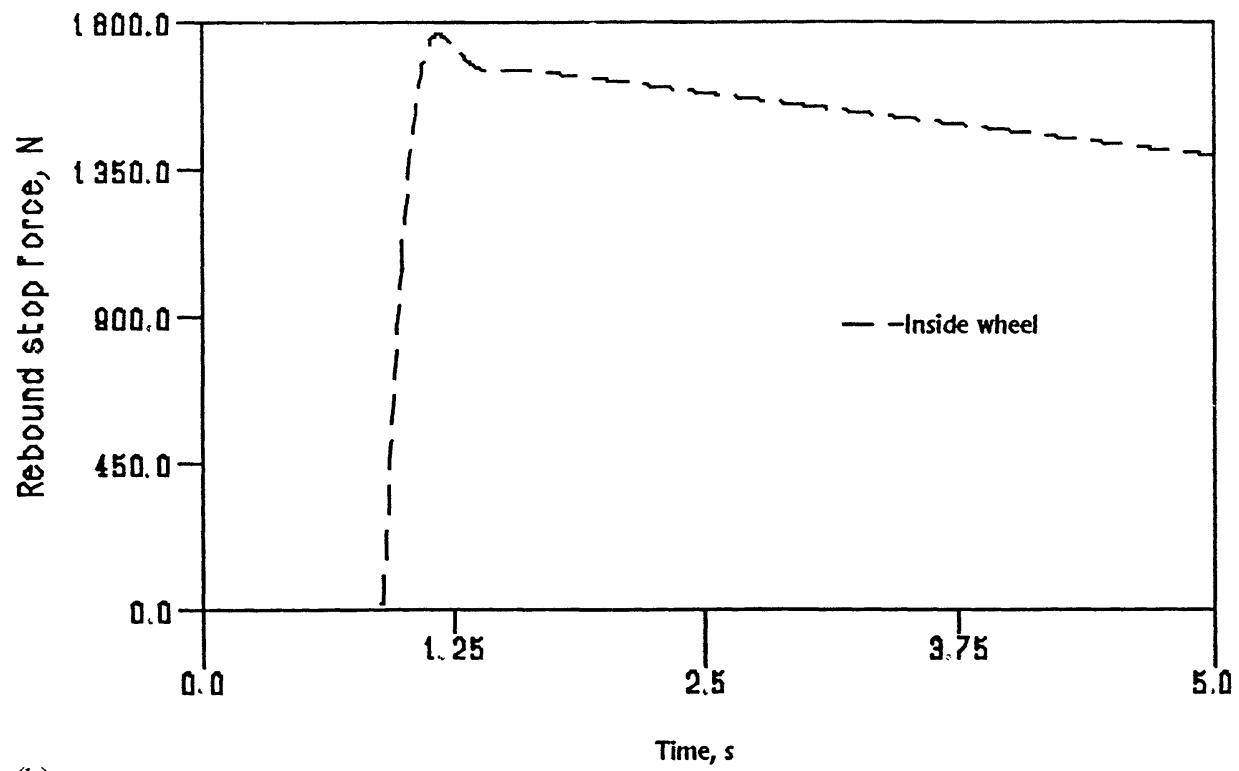

Fig. 8 (a) Bump stop forces for front tyres and (b) rebound stop forces for front tyres

function. Under this test, the variations in the response (i.e. roll angle, lateral acceleration and yaw rate) can be obtained as measures of vehicle performance. Figures $9 \mathrm{~b}$ and $\mathrm{c}$ illustrate the lateral acceleration and roll angle change for the step steering input shown in Fig. 5 and equation (19). Both the lateral acceleration and the roll angle rise with an increasing steering angle. The maximum steering angle is $40^{\circ}$, reached after $0.3 \mathrm{~s}$. In this standard transient response test the vehicle response time is defined as the period taken for the vehicle to reach 90 per cent of the maximum response value, if the origin of the time base is set at the point where half the maximum steering input has been accomplished. The response time for the lateral acceleration is, therefore, $0.39 \mathrm{~s}$ (see Fig. 9b). The peak response time is also measured in the same time frame. This is also shown in the same figure and is $0.56 \mathrm{~s}$. The parameters of interest in this transient analysis are the response time, the peak response time and the lateral acceleration overshoot. Clearly, optimal conditions relate to the minimization of all of these parameters. The same parameters can also be measured from the variation in roll angle in Fig. 9c. These are shown in the figure. 


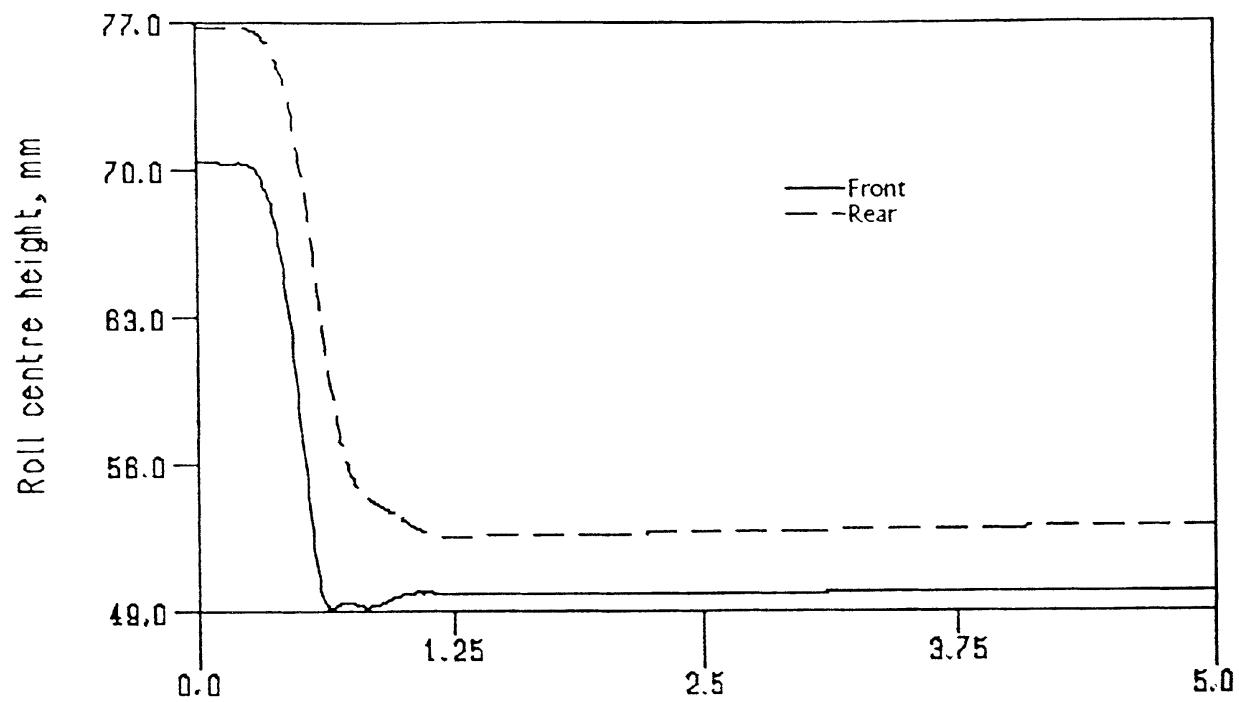

(a)

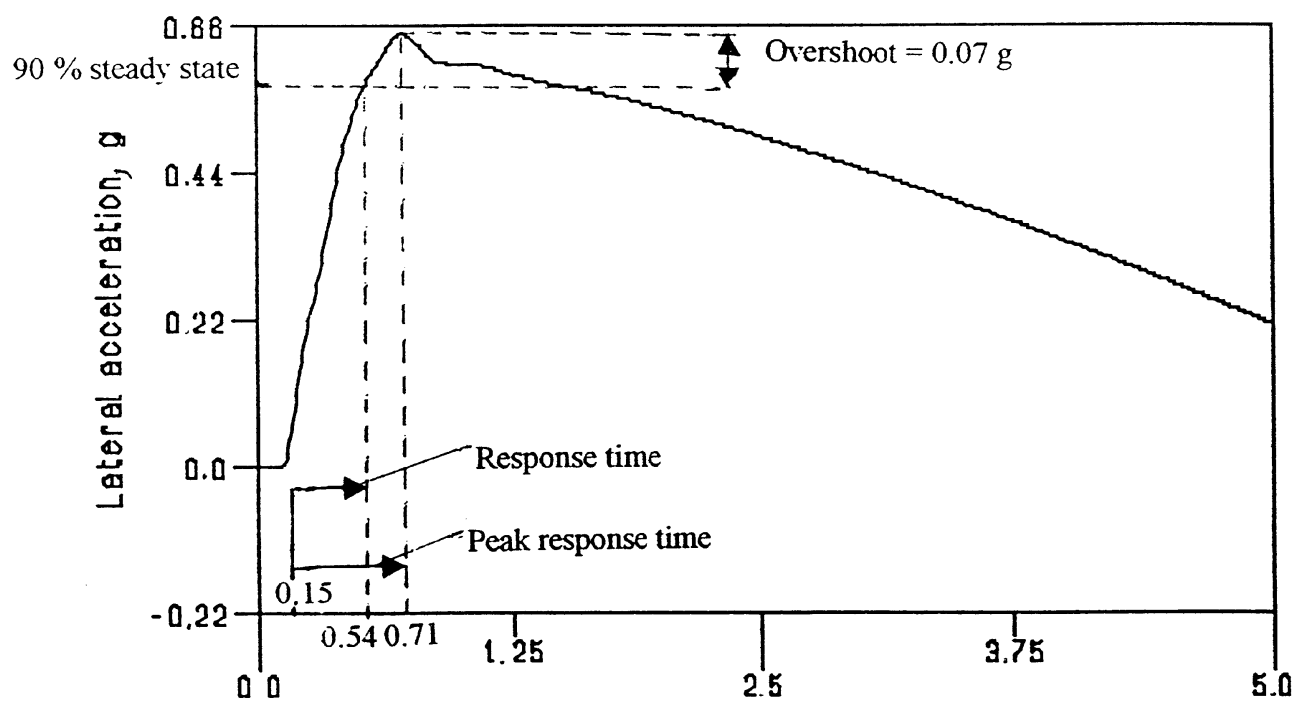

(b)

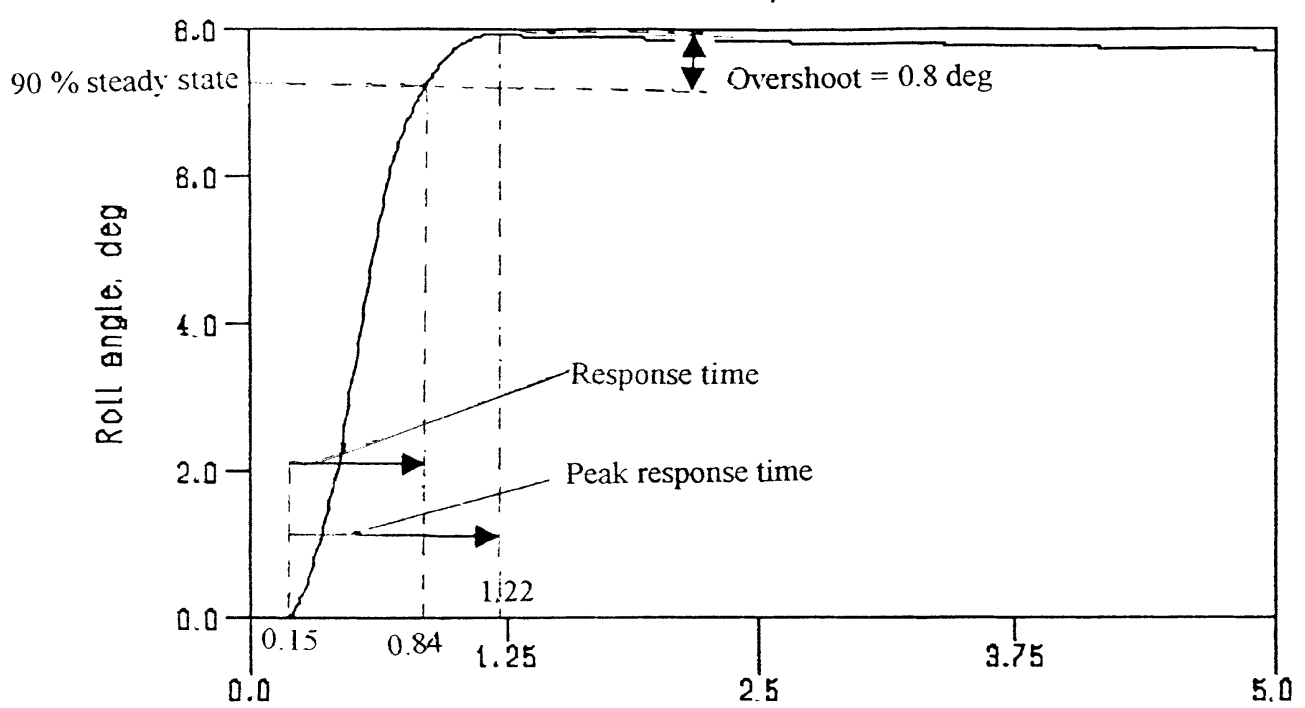

(c)

Time, sec

Fig. 9 (a) Instantaneous roll centre height variation, (b) lateral acceleration variation with time and (c) vehicle body roll angle variation with time 


\section{CONCLUSION}

This paper has shown the use of multi-body dynamics in vehicle handling analysis. This approach is particularly useful under transient conditions arising from the application of a steering function. A non-linear dynamic analysis for a realistic multi-degrees-of-freedom vehicle model (having 94 degrees of freedom) subjected to a step steering function has been presented. The results of such an analysis can be used to measure the vehicle 'responsiveness' in terms of given parameters specified in ISO and BS standards for non-steady conditions. The extent of lateral acceleration overshoot, roll angle variation and generated vertical tyre forces, particularly on the inside wheels, in turn can provide a good measure of vehicle stability. The simulation highlighted in the paper indicates that sufficient tyre forces are generated, ensuring vehicle adherence to its path. The change in the roll angle is within the specified limit for the type of vehicle under investigation. The vehicle lateral acceleration overshoot is $0.07 \mathrm{~g}$ and its response time to the steering input is adequately short. The procedure highlighted in this paper can be employed for simulation of vehicle models under transient manoeuvres. A large amount of proprietary physical and geometrical data has been included in the paper which can be used by others who intend to carry out similar vehicle handling studies.

\section{ACKNOWLEDGEMENT}

The authors wish to express their gratitude to the Egyptian Military Attaché's Office for the financial support extended to this research project.

\section{REFERENCES}

1 Segel, L. Theoretical prediction and experimental substantiation of the response of the automobile to steering control, in research in automobile stability and control and in tyre performance. Proc. Instn Mech. Engrs, 1956-7, (7), 310-330.

2 McHenry, R. R. An analysis of the dynamics of automobiles during simultaneous cornering and ride motions, in handling of vehicles under emergency conditions. Proc. Instn Mech. Engrs, 1968-9, (13), 28-48.

3 Chace, M. A. Methods and experience in computer aided design of large displacement mechanical systems. Computer Aided Analysis and Optimization of Mechanical System Dynamics, Nato ASI Series, F9, 1984, pp. 233-259.

4 Orlandea, N., Chace, M. A. and Calahan, D. A. A sparsity- oriented approach to the dynamic analysis and design of mechanical systems, Parts I and II. Trans. ASME, J. Engng for Industry, 1977, 99, 773-784.

5 Orlandea, N. and Chace, M. A. Simulation of a vehicle suspension with ADAMS computer program. SAE Technical paper 770053, 1977.

6 Allen, R. W., Rosenthal, T. J. and Szostak, T. H. Steady state and transient analysis of ground vehicle handling. SAE Technical paper 870495, 1987, pp. 49-78.

7 Pacejka, H. B. Simplified analysis of steady state turning behaviour of motor vehicle-Part 1: handling diagram of simple system. Veh. Syst. Dynamics, 1973, 2, 161-172.

8 Naude, A. F. and Steyn, J. L. Objective evaluation of the simulated handling characteristics. SAE Technical paper 930826, 1993, pp. 97-102.

9 Pacejka, H. B. and Sharp, R. S. Shear force development by pneumatic tyres in steady state condition: a review of modelling aspects. Veh. Syst. Dynamics, 1991, 20, 121-176.

10 Pacejka, H. B. and Bakker, E. The Magic Formula tire model. Veh. Syst. Dynamics, 1993, 21, 1-18.

11 Allen, R. W., Christos, J. B. and Rosenthal, T. J. A tire model for use with vehicle dynamics simulations on pavement and off-road surfaces. Veh. Syst. Dynamics, 1997, 27, 318321.

12 Allen, R. W., Magdaleno, R. E., Rosenthal, T. J., Klyde, D. H. and Hogue, J. R. Tire modelling requirements for vehicle dynamics simulations. SAE Technical paper 950312, 1995, pp. $95-115$.

$13 \mathrm{Xia}, \mathbf{X}$. and Willis, J. N. The effect of tire cornering stiffness on vehicle linear handling performance. SAE Technical paper 950313, 1995, pp. 117-126.

14 Kortüm, W. and Sharp, R. S. Multi-body Computer Codes in Vehicle System Dynamics, 1973 (Swets und Zeitlinger, Amsterdam).

15 Kortüm, W. and Schiehlen, W. General purpose vehicle system dynamics software based on multi-body formalisms. Veh. Syst. Dynamics, 1985, 14, 229-263.

16 Kübler, R. and Schiehlen, W. Vehicle modular simulation in system dynamics. In Transactions of IMechE Conference on Multi-body Dynamics: New Techniques and Applications, London, 1998, paper C553/039/98, pp. 249-258.

17 ADAMS/Tyre User's Guide-Version 5.2, October 1987 (Mechanical Dynamic Inc.).

18 Rahnejat, H. Multi-body Dynamics: Vehicles, Machines and Mechanisms, July 1998 (Professional Engineering Publishing, Bury St Edmunds, UK; Society of Automotive Engineers, Warrendale, Pennsylvania, USA).

19 Gear, C. W. Simultaneous numerical solution of differentialalgebraic equations. Circuit Theory, 1971, 18, 89-95.

20 Gear, C. W. The numerical solution of problems which may have high frequency components. In Proceedings of NATO ASI on Computer Aided Analysis and Optimization of Mechanical System Dynamics, 1984 (Springer-Verlag).

21 British Standard Automobile Series, BS AU 230, Lateral transient response behaviour of passenger cars, 1989 (British Standards Institution). 